\title{
Bronchopulmonary dysplasia frequency and risk factors in very low birth weight infants: A 3-year retrospective study
}

\author{
(D) Turgay Cokyaman, (D) Sultan Kavuncuoglu \\ Department of Pediatrics, Istanbul Bakirkoy Maternity and Children's Research and Training Hospital, Istanbul, Turkey
}

\begin{abstract}
OBJECTIVE: In this study, the relationship between the frequency of bronchopulmonary dysplasia, perinatal risk factors and other prematurity comorbidities were evaluated in very low birth weight infants.

METHODS: A total of 872 very low birth weight infants' files were retrospectively reviewed. The effects of the clinical parameters, such as type of birth, small for gestational age, gender, antenatal steroids, early membrane rupture, chorioamnionitis, surfactant administration, respiratory distress syndrome, patent ductus arteriosus, apnea, early and late sepsis on the frequency of bronchopulmonary dysplasia, were evaluated by binary logistic regression analysis.

RESULTS: The overall mortality rate was $20.9 \%$. After the first 28-day mortality reduction, the total bronchopulmonary dysplasia frequency was found to be $20.1 \%$. The odds ratio and $95 \%$ confidence intervals of the factors affecting the development of bronchopulmonary dysplasia were found to be as follows respectively: respiratory distress syndrome (OR 6.2, 95\% CI 3.6-10.6, $\mathrm{p}<0.01$ ), patent ductus arteriosus (OR 4.9, 95\% Cl 2.4-9.9, $\mathrm{p}<0.01$ ), apnea (OR 4.1, 95\% CI 2.5-6.9, $\mathrm{p}<0.01$ ), late sepsis (OR 2.7, 95\% CI 1.6-4.5, $\mathrm{p}<0.01$ ), early membrane rupture ( $\mathrm{OR} 2.6,95 \% \mathrm{Cl} 1.2-5.5, \mathrm{p}=0.01$ ), and male gender (OR 1.6, 95\% CI 1.0-2.7, p=0.04) was found. However, there was no effect of chorioamnionitis, antenatal steroids, small for gestational age, early sepsis and type of birth on bronchopulmonary dysplasia.

CONCLUSION: Differently from the usual factors which are low birth weight and a gestational week, there was a significant but non-linear risk relationship between respiratory distress syndrome, patent ductus arteriosus, late sepsis, apnea, early membrane rupture, male gender and bronchopulmonary dysplasia.

Keywords: Bronchopulmonary dysplasia; premature infant.

Cite this article as: Cokyaman T, Kavuncuoglu S. Bronchopulmonary dysplasia frequency and risk factors in very low birth weight infants: A 3-year retrospective study. North Clin Istanb 2020;7(2):124-130.
\end{abstract}

$\mathrm{B}$ ronchopulmonary dysplasia (BPD) is a chronic lung disease requiring long-term oxygen support with $\geq 21 \%$ concentration with a variety of modalities in premature infants. Until the 2000s, the diagnosis was made based on whether oxygen requirements continued up to the postnatal $28^{\text {th }}$ day. However, after this date, diagnosis began to be made based on the severity of the disease as mild, moderate and severe according to gestational week $(\mathrm{GW})[1,2]$. Low birth weight (WB) and GW are usual risk factors for BPD, and there is an inverse linear relationship between them.
Perinatal risk factors like a cesarean section, male gender, antenatal corticosteroids, EMR, chorioamnionitis, SGA, postnatal surfactant, RDS, early and late-onset sepsis, PDA and apnea are reported to be associated with BPD [3]. According to centers, the incidence of $\mathrm{BPD}$ in $<32 \mathrm{GW}$ premature infants was reported to be $30 \%$ in the United States, $12 \%$ in Canada and $14 \%$ in Japan $[4,5]$. In this study, the relationship of BPD frequency, perinatal risk factors and other prematurity comorbidities were assessed for very low birth weight (VLBW) infants.

Received: June 18, 2019 Accepted: July 17, 2019 Online: August 09, 2019

Correspondence: Dr. Turgay COKYAMAN. Istanbul Bakirkoy Dogum ve Cocuk Arastirma ve Egitim Hastanesi, Pediatri Anabilim Dali, Istanbul, Turkey. 


\section{MATERIALS AND METHODS}

Medical files of 872 VLBW infants between January 1, 2006, and December 31, 2008, were retrospectively reviewed. Ethical approval was granted by the hospital's ethics committee (date: 29/04/2009 and decision number: 220) was obtained before infants were enrolled in this study. Infants with multiple system anomalies or chromosomal anomalies were excluded from this study. Mortality rates for the first 28 days were determined according to BW and GW. Regardless of GW, diagnosed with BPD if there is an infant with continuing $\geq 21 \%$ concentration oxygen support for postnatal 28 days or longer. After removing the first 28-day mortalities, the remainder were separated into two groups as BPD $(+)$ and (-). All babies had BW, GW, type of birth (vaginal or cesarean), whether they had small for gestational age (SGA), gender, antenatal corticosteroids, early membrane rupture (EMR), chorioamnionitis, postnatal surfactant administration, respiratory distress syndrome (RDS), patent ductus arteriosus (PDA), apnea, early and late-onset sepsis, periventricular leukomalacia (PVL) and total hospitalization recorded.

\section{Statistical Analysis}

Statistical analyses were performed on SPSS (SPSS Inc. Chicago, IL, USA) version 15 for Windows software. Comparisons between the groups used the Pearson chisquare test and independent groups $t$-test or Mann-Whitney $U$ test based on the type and distribution of variables. The effects of independent variables on BPD were calculated with the binary logistic regression (backward conditional model) analysis after removing that mortality within the first 28 days. For the validity of the regression model, the Hosmer-Lemeshow test $p>0.05$ condition was ensured. To determine risk levels, the odds ratios (OR) and the $95 \%$ confidence interval $(\mathrm{CI})$ were used. For all calculations, $\mathrm{p}<0.05$ was accepted as significant.

\section{RESULTS}

The mortality rates, according to BW and GW, are presented in Figure 1. According to this figure, total mortality was $20.9 \%(182 / 872)$ and it appeared mortality increased in inverse linear ratio to the BW and GW. After removing mortalities in the first 28 days, total BPD incidence was $20.1 \%(139 / 690)$ and, similar to mortality, the incidence of BPD increased in inverse linear ratio to the BW and GW (Fig. 2).

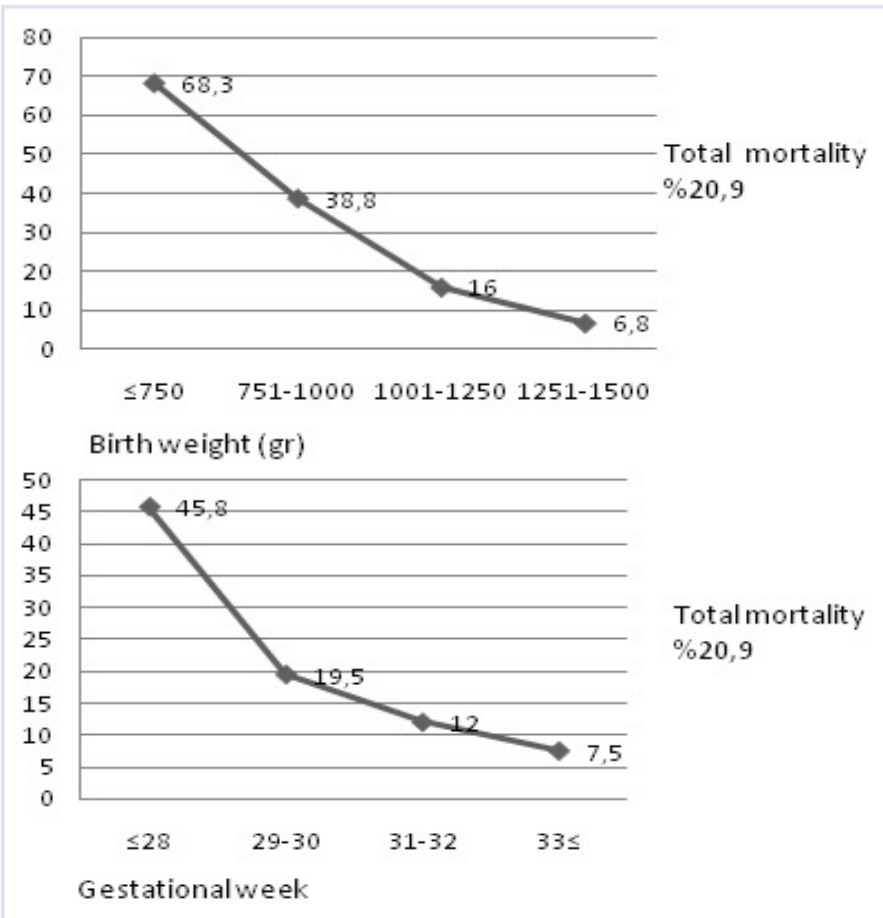

FIGURE 1. (A) Mortality rates according to birth weight and (B) gestational week.

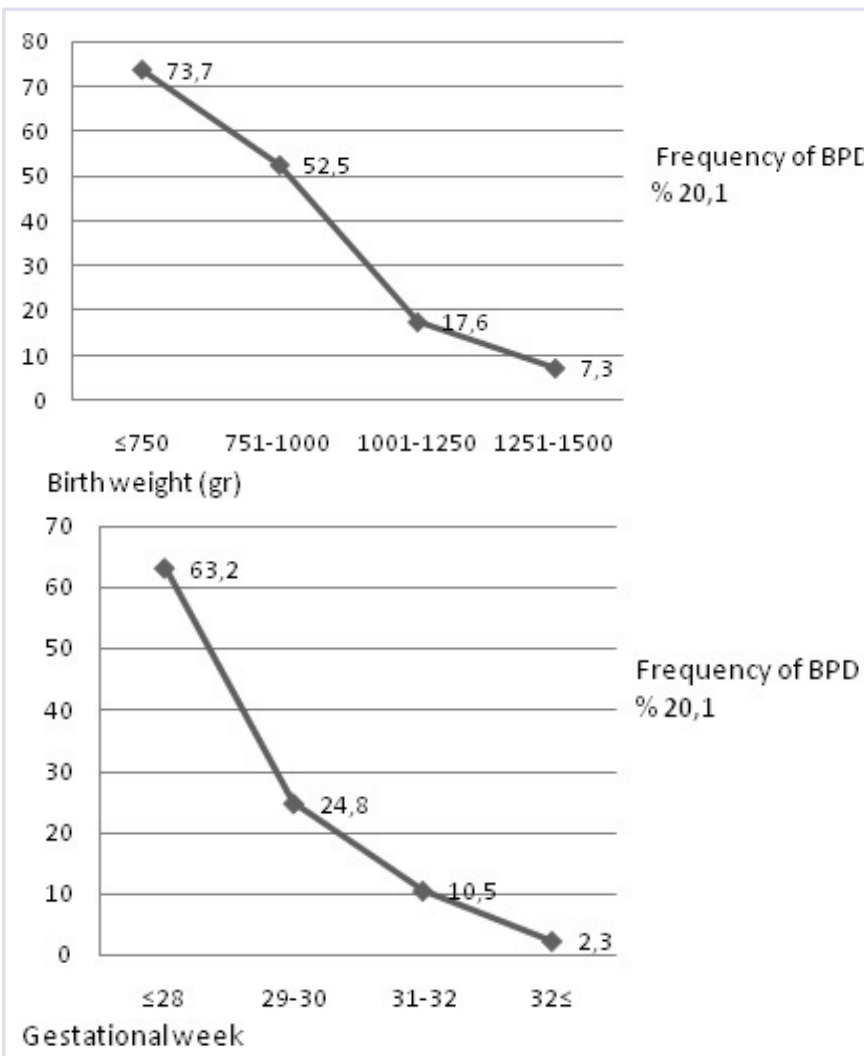

FIGURE 2. (A) Frequency of bronchopulmonary dysplasia (BPD) according to birth weight and (B) gestational weeks. 
The mean BW and GW were found to be significantly different between the BPD (+) and (-) groups. Cesarean section, male gender, antenatal corticosteroids, chorioamnionitis, postnatal surfactant administration, RDS, PDA, apnea and late-onset sepsis were significantly high in the BPD (+) group except for EMR, SGA and early-onset sepsis. The significant prematurity comorbidities, such as PVL and total hospitalization, were elevated significantly in the BPD $(+)$ group $(\mathrm{p}<0.01$, Table 1$)$.

TABLE 1. Comparison of perinatal risk factors and comorbidities between BPD (+) and (-) groups

\begin{tabular}{|c|c|c|c|}
\hline & $\begin{array}{l}\text { BPD (+) } \\
(n=139)\end{array}$ & $\begin{array}{l}\text { BPD (-) } \\
(n=551)\end{array}$ & $\mathrm{p}$ \\
\hline Birth weight (gr) & $1014 \pm 217$ & $1262 \pm 177$ & $<0.01^{\ddagger}$ \\
\hline Gestational week & $28.3 \pm 2.3$ & $31.8 \pm 2.2$ & $<0.01^{\ddagger}$ \\
\hline Caesarean section & $\begin{array}{l}66.2 \% \\
(n=92)\end{array}$ & $\begin{array}{c}78.2 \% \\
(n=430)\end{array}$ & $0.03 *$ \\
\hline SGA & $\begin{array}{l}14.4 \% \\
(n=20)\end{array}$ & $\begin{array}{c}18.7 \% \\
(n=103)\end{array}$ & $0.23 *$ \\
\hline Male gender & $\begin{array}{l}59.0 \% \\
(n=82)\end{array}$ & $\begin{array}{c}40.3 \% \\
(n=222)\end{array}$ & $<0.01 *$ \\
\hline Antenatal corticosteroid & $\begin{array}{l}14.4 \% \\
(n=20)\end{array}$ & $\begin{array}{l}\% 3.3 \% \\
(n=18)\end{array}$ & $<0.01 *$ \\
\hline EMR & $\begin{array}{l}18.0 \% \\
(n=25)\end{array}$ & $\begin{array}{l}12.0 \% \\
(n=66)\end{array}$ & $0.06 *$ \\
\hline Chorioamnionitis & $\begin{array}{l}5.8 \% \\
(n=8)\end{array}$ & $\begin{array}{l}0.9 \% \\
(n=5)\end{array}$ & $0.01 *$ \\
\hline Postnatal surfactant & $\begin{array}{l}68.3 \% \\
(n=95)\end{array}$ & $\begin{array}{l}15.8 \% \\
(n=87)\end{array}$ & $<0.01 *$ \\
\hline RDS & $\begin{array}{c}77.7 \% \\
(n=108)\end{array}$ & $\begin{array}{c}22.4 \% \\
(n=123)\end{array}$ & $<0.01 *$ \\
\hline PDA & $\begin{array}{l}29.4 \% \\
(n=41)\end{array}$ & $\begin{array}{c}4.6 \% \\
(n=25)\end{array}$ & $<0.01 *$ \\
\hline Apnea & $\begin{array}{l}69.8 \% \\
(n=97)\end{array}$ & $\begin{array}{c}18.7 \% \\
(n=103)\end{array}$ & $0.01 *$ \\
\hline Early onset sepsis & $\begin{array}{l}10.8 \% \\
(n=15)\end{array}$ & $\begin{array}{l}11.0 \% \\
(n=61)\end{array}$ & 0.92 \\
\hline Late onset sepsis & $\begin{array}{l}64.0 \% \\
(n=87)\end{array}$ & $\begin{array}{l}17.8 \% \\
(n=98)\end{array}$ & $<0.01 *$ \\
\hline PVL & $\begin{array}{c}9.4 \% \\
(n=13)\end{array}$ & $\begin{array}{l}1.6 \% \\
(n=9)\end{array}$ & $<0.01 *$ \\
\hline Total hospitalization (days) & $64.4 \pm 22.2$ & $26.7 \pm 16.5$ & $<0.01^{\mu}$ \\
\hline
\end{tabular}

BPD: Bronchopulmonary dysplasia; SGA: Small for gestational age; EMR: Early membrane rupture; RDS: Respiratory distress syndrome; PDA: Patent ductus arteriosus; PVL: Periventricular leukomalacia; *: Pearson Chi-square test; $\neq$ : independent $t$ test; $\mu$ : Mann Whitney $U$ test.
The effects of categorical independent variables of type of birth (cesarean section), SGA, male gender, antenatal corticosteroids, EMR, chorioamnionitis, postnatal surfactant administration, RDS, PDA, apnea and early and late-onset sepsis on BPD incidence were assessed with binary logistic regression analysis (Table 2). Due to the very close correlation of postnatal surfactant and RDS frequencies, calculations only included RDS in the model as a variable. RDS, PDA, apnea, late-onset sepsis, EMR and male gender were observed to be risk factors increasing the development of BPD. Contrary to this, chorioamnionitis and administration or not of antenatal corticosteroid were understood not to form a risk for BPD. In this analysis, SGA did not have a significant contribution in the second step, early-onset sepsis in the third step and type of birth in the fourth step. Thus they were removed from the calculations of the regression model.

\section{DISCUSSION}

Bronchopulmonary dysplasia incidence is reported in the United States of America as 52\% for 501-750 g BW, $34 \%$ for $751-1000 \mathrm{~g}, 15 \%$ for $1001-1250 \mathrm{~g}$ and $7 \%$ for 1251-1500 g [6]. In Switzerland, it was found to be $16.7 \%$ for infants $<1500 \mathrm{~g}$ in 1996 and $13.2 \%$ in 2000 [7]. It is reported as $18 \%$ in Denmark, $15 \%$ in France, $40 \%$ of $<26 \mathrm{GW}$ premature infants and $29 \%$ for $<32$ GW premature infants in Germany [8-10]. In our study, the incidence of BPD was $73.7 \%$ for $\leq 750 \mathrm{~g}$ infants, $52.5 \%$ for $751-1000 \mathrm{~g}$ infants, $17.6 \%$ for $1001-$

TABLE 2. The possible effects of perinatal risk factors on BPD development

\begin{tabular}{lccc} 
Risk factors & OR & $\% 95 \mathrm{CI}$ & $\mathrm{p}$ \\
\hline RDS & 6.2 & $3.6-10.6$ & $\mathbf{< 0 . 0 1}$ \\
PDA & 4.9 & $2.4-9.9$ & $\mathbf{< 0 . 0 1}$ \\
Apnea & 4.1 & $2.5-6.9$ & $\mathbf{< 0 . 0 1}$ \\
Late onset sepsis & 2.7 & $1.6-4.5$ & $<\mathbf{0 . 0 1}$ \\
EMR & 2.6 & $1.2-5.5$ & $\mathbf{0 . 0 1}$ \\
Male gender & 1.6 & $1.0-2.7$ & $\mathbf{0 . 0 4}$ \\
Chorioamnionitis & 3.7 & $0.8-16.1$ & 0.07 \\
Antenatal corticosteroid & 0.42 & $0.1-1.0$ & 0.05
\end{tabular}

BPD: Bronchopulmonary dysplasia; OR:Odds ratio; CI: Confidence interval; RDS: Respiratory distress syndrome; PDA: Patent ductus arteriosus; EMR: Early membrane rupture. 
$1250 \mathrm{~g}$ infants and $7.3 \%$ for $1251-1500 \mathrm{~g}$ infants with a total incidence of $20.1 \%$. According to GW, BPD was present in $63.2 \%$ of $\leq 28 \mathrm{GW}$ infants, $24.8 \%$ of $29-30$ GW infants, $10.5 \%$ of $31-32 \mathrm{GW}$ infants and $2.3 \%$ of $33 \leq \mathrm{GW}$ infants (Fig. 2).

In calculations with postnatal surfactant included in the regression model as a risk factor, the preventive effect on BPD was significant; however, the power was low (OR 0.42, 95\% CI 0.20-0.91, p=0.029). Due to the close correlation between postnatal surfactant and RDS, postnatal surfactant was not included in the model. RDS was determined to be the strongest risk factor for BPD in the regression model (OR 6.2, 95\% CI 3.6-10.6, $\mathrm{p}<0.01$, Table 2). In the process of developing BPD, the majority of infants initially experience RDS and many have postnatal surfactant administered. As a result, a secondary triggering factor for BPD after prematurity may be said to be RDS [11].

When we examine PDA, this study revealed it was the second effective risk factor for BPD (OR 4.9, 95\% CI 2.4-9.9, $\mathrm{p}<0.01$, Table 2). However, in the current literature, there is controversy as to whether it is a risk factor for BPD or not. The results of prophylactic PDA closure studies with surgery or medication, such as indomethacin, have shown no effect on BPD and mortality outcomes [12-14]. However, the volutrauma effects of PDA on premature lungs cannot be ignored and it is clear this mechanical trauma increases the severity of RDS, and as a result, may cause BPD [15].

There is strong evidence that sepsis and systemic inflammation disrupts the vascular permeability of the lungs causing structural injury and long-term alveolarization disorder $[16,17]$. As a result, sepsis alone is accepted as an independent risk factor for BPD [18]. A study by Lahra et al. (2009) reported that the development of postnatal sepsis increased the incidence of BPD and emphasized postnatal inflammation rather than antenatal [19]. A study by Eriksson et al. (2014) partly supports this by showing that inflammatory diseases before pregnancy do not affect the incidence of BPD [20]. Studies related to early-onset sepsis reported BPD and other premature comorbidities significantly increased $[21,22]$. In our study, there was no risk correlation identified between early-onset sepsis and BPD; however, a significant correlation was shown for late-onset sepsis (OR 2.7, 95\% CI 1.6-4.5, p<0.01, Table 2).

Intermittent hypoxic episodes and a variety of forms of apnea are commonly observed in preterms, and ex- cess free radicals occur during these attacks, especially in the lungs [23]. The weakness of central and peripheral chemosensitive respiratory control mechanisms or airway and pulmonary compliance disorders may cause hypoxic attacks in BPD [24]. As a result, apnea may be both a cause and a result of BPD. In our study, a link between apnea and BPD was identified and it was understood to be an effective risk factor (OR 4.1, 95\% CI 2.5-6.9, $\mathrm{p}<0.01$, Table 2).

Early membrane rupture is responsible for nearly $1 / 3$ of preterm births and the etiology is multifactorial [25]. EMR begins with local inflammation and ascendant bacterial colonization due to the stretching of the membranes in the early period [26]. The possible fetal effects of EMR are not clearly understood because mild perinatal inflammation is reported to have possible positive effects on fetal immune system maturation [27]. Comprehensive research published by the German Neonatal Group in 2015 revealed that EMR was only a risk factor for BPD in the chronic period (OR 1.25, 95\% CI 1.02$1.55, \mathrm{p}=0.03$ ) [28]. In our study, this risk level was found to be higher (OR 2.6, 95\% CI 1.2-5.5, p=0.01, Table 2).

Some studies have reported cesarean birth increases the risk of BPD $[29,30]$. In this study, the cesarean birth rate was identified to be high in the $\mathrm{BPD}(+)$ group; however, no risk correlation was identified with regression analysis $(p>0.05)$. Here, the noteworthy situation is that the cesarean birth rate for preterm infants has increased through the years independently of BPD. BPD tends to occur with the male gender and it is reported to be observed 2-5 times more frequently in male infants $[31,32]$. In our study, this possible risk was identified at low levels (OR 1.6, 95\% CI 1.0-2.7, p=0.04, Table 2).

Although postnatal infections like pneumonia and sepsis are accepted as risk factors for the development of $\mathrm{BPD}$, the situation for prenatal infections like chorioamnionitis is not clear [33]. Chronic fetal inflammation linked to chorioamnionitis may affect the pulmonary development of the infant in very bad or good ways [34]. Some studies published recently have shown EMR and chorioamnionitis as the most common causes of preterm births, but emphasize that chorioamnionitis does not increase the BPD risk for VLBW infants $[35,36]$. In this study, chorioamnionitis was not determined to be a risk factor for BPD ( $p=0.07$, Table 2$)$.

Antenatal corticosteroids reduce the severity of RDS and as a result reduce the incidence of BPD [37]. However, different studies have shown, contrarily, that ad- 
ministration does not affect BPD incidence [38-40]. In developed countries, antenatal corticosteroids administration is reported at levels of $60-70 \%[6,29,41]$. In our study, antenatal corticosteroids were administered to $14.4 \%$ in the BPD (+) group and 3.3\% in the BPD (-) group $(p<0.01$, Table 1$)$. Although very different rates of administration have been found among the groups, antenatal steroid administration is not a significant risk factor for BPD ( $>>0.05)$.

In SGA infants, pulmonary maturation occurs earlier due to chronic stress exposure and linked to this effect, the incidence and severity of RDS reduce [42]. Some studies have reported the protective effect of SGA in premature infants later than $32 \mathrm{GW}$ reduces the incidence of RDS, while it does not change or possibly increases the incidence of RDS for those below 32 GW [43-47]. Many studies have revealed that BPD and late-period pulmonary complications are observed more often in SGA preterm $[48,49]$. In our study, the SGA preterm rate was $14.4 \%$ in the $\mathrm{BPD}(+)$ group and $18.7 \%$ in the $\mathrm{BPD}(-)$ group; however, there was no significant difference between the groups $(p=0.23$, Table 1$)$. The regression model revealed that SGA was not a possible risk factor for BPD ( $p>0.05)$. This situation may be explained by embryological development stages of the fetal lungs and postmortem pathologic findings. Postmortem investigations have reported that although BPD infants have acinar development and alveolar stage completion in fetal lungs, the saccular development stage is stopped [50]. In our study, the majority of BPD infants were preterm below $32 \mathrm{GW}$ and according to Figure 2, the incidence of BPD rapidly reduces above $32 \mathrm{GW}$. According to our findings, SGA is understood not to be a possible risk factor affecting $\mathrm{BPD}$.

RDS in BPD (+) and (-) groups at very different frequencies of this study (Table 1), rather than birth weight, based on the opinion of gestation week, brings the idea of design. The concept of VLBW in the literature has some problems in evaluating fetal lung development. Because as the birth weight increases to 1500 grams, gestation week approaches 32 weeks, and this period is critical for fetal lung maturation and BPD decreases rapidly after this period. Also, there is no risk relation between SGA and BPD partially supports this observation.

The new BPD defined in recent years is characterized by dysmorphic vascularization with fewer and larger alveolar structures due to abnormal postnatal lung development in very preterm and ELBW infants. Factors associated with mechanical ventilation, such as oxygen toxicity, barotrauma, and volutrauma, are known to play a role in the etiology of BPD [51]. Therefore, lung-protective mechanical ventilation strategies have been developed in recent years to reduce the incidence of BPD.

In our study, having oxygen supplementation in postnatal $28^{\text {th }}$ day and over was used for the diagnostic criterion of BPD regardless of GW. Since postnatal $36^{\text {th }}$-week oxygen support levels were not known, the classification of according to new BPD criteria could not be classified. Also, the use of conventional mechanical ventilation methods during the study period made it difficult to evaluate the effects of invasive oxygen treatment modalities on BPD. These two conditions are important limitations of this study and obstructed the subgroup classification and analysis of related risk factors of new BPD.

Another limitation is that the study findings are not supported by laboratory findings, such as inflammatory markers (CRP, procalcitonin, IL-1 and 6) or free radical levels. These laboratory findings may provide insight into the mechanism of inflammatory factors, such as sepsis, EMR and chorioamnionitis in the pathophysiology of BPD.

In this study, the low antenatal corticosteroid administration rate (5.9\% of VLBW infants) may be explained by pregnant women monitored at external centers being rapidly sent to our center, which is the largest and most well-known maternity hospital in the region, due to early labor. This situation usually causes the accumulation of a special group instead of a random group concerning statistics. However, in spite of this asymmetric case accumulation, regression analysis showed antenatal corticosteroid administration or lack of administration had no effect on BPD ( $p>0.05$, Table 2 ). As a result, in developing countries, such as ours, the low antenatal steroid administration rate is an expected situation. In spite of the low antenatal corticosteroid administration rate, it is noteworthy that the incidence of BPD in developing countries is close to that of developed countries.

To conclude, RDS, PDA, apnea, late-onset sepsis, $\mathrm{EMR}$, and male gender were associated with the risk of BPD in preterm infants. There was no relationship between BPD and chorioamnionitis, antenatal corticosteroids, cesarean birth, early-onset sepsis, and SGA. Further large studies are needed to understand the real effects of these factors that cannot be related to BPD. 
Ethics Committee Approval: Ethical approval was granted by the hospital's ethics committee (date: 29/04/2009 and decision number: 220) was obtained before infants were enrolled in this study.

Conflict of Interest: No conflict of interest was declared by the authors.

Financial Disclosure: The authors declared that this study has received no financial support.

Authorship Contributions: Concept - TC, SK; Design - TC, SK; Supervision - TC, SK; Fundings - TC, SK; Materials - TC, SK; Data collection and/or processing - TC; Analysis and/or interpretation - TC, SK; Literature review - TC, SK; Writing - TC; Critical review $-\mathrm{TC}, \mathrm{SK}$.

\section{REFERENCES}

1. Northway WH Jr, Rosan RC, Porter DY. Pulmonary disease following respirator therapy of hyaline-membrane disease. Bronchopulmonary dysplasia. N Engl J Med 1967;276(7):357-68. [CrossRef]

2. Jobe AH, Bancalari E. Bronchopulmonary dysplasia. Am J Respir Crit Care Med 2001;163:1723-9. [CrossRef]

3. Bancalari E, Claure N, Sosenko IR. Bronchopulmonary dysplasia: changes in pathogenesis, epidemiology and definition. Semin Neonatol 2003;8:63-71. [CrossRef]

4. Horbar JD, Carpenter JH, Badger GJ, Kenny MJ, Soll RF, Morrow KA, et al. Mortality and neonatal morbidity among infants 501 to 1500 grams from 2000 to 2009. Pediatrics 2012;129:1019-26. [CrossRef]

5. Isayama T, Lee SK, Mori R, Kusuda S, Fujimura M, Ye XY, et al; Canadian Neonatal Network; Neonatal Research Network of Japan. Comparison of mortality and morbidity of very low birth weight infants between Canada and Japan. Pediatrics 2012;130:e957-65. [CrossRef]

6. Lemons JA, Bauer CR, Oh W, Korones SB, Papile LA, Stoll BJ, et al. Very low birth weight outcomes of the National Institute of Child health and human development neonatal research network, January 1995 through December 1996. NICHD Neonatal Research Network. Pediatrics 2001;107:E1. [CrossRef]

7. Hentschel J, Berger TM, Tschopp A, Müller M, Adams M, Bucher HU; Swiss Neonatal Network. Population-based study of bronchopulmonary dysplasia in very low birth weight infants in Switzerland. Eur J Pediatr 2005;164:292-7. [CrossRef]

8. Kamper J, Feilberg Jørgensen N, Jonsbo F, Pedersen-Bjergaard L, Pryds O; Danish ETFOL Study Group. The Danish national study in infants with extremely low gestational age and birthweight (the ETFOL study): respiratory morbidity and outcome. Acta Paediatr 2004;93:225-32.

9. Egreteau L, Pauchard JY, Semama DS, Matis J, Liska A, Romeo B, et al. Chronic oxygen dependency in infants born at less than 32 weeks' gestation: incidence and risk factors. Pediatrics 2001;108:E26. [CrossRef]

10. Thomas W, Speer CP. Management of infants with bronchopulmonary dysplasia in Germany. Early Hum Dev 2005;81:155-63. [CrossRef]

11. Jobe AH, Tibboel D. Update in pediatric lung disease 2013. Am J Respir Crit Care Med 2014;189:1031-6. [CrossRef]

12. Ohlsson A, Walia R, Shah SS. Ibuprofen for the treatment of patent ductus arteriosus in preterm or low birth weight (or both) infants. Cochrane Database Syst Rev 2015:CD003481. [CrossRef]

13. Schmidt B, Roberts RS, Fanaroff A, Davis P, Kirpalani HM, Nwaesei $\mathrm{C}$, et al; TIPP Investigators. Indomethacin prophylaxis, patent ductus arteriosus, and the risk of bronchopulmonary dysplasia: further analyses from the Trial of Indomethacin Prophylaxis in Preterms (TIPP). J
Pediatr 2006;148:730-4. [CrossRef]

14. Benitz WE. Treatment of persistent patent ductus arteriosus in preterm infants: time to accept the null hypothesis? J Perinatol 2010;30:24152. [CrossRef]

15. Schena F, Francescato G, Cappelleri A, Picciolli I, Mayer A, Mosca F, et al. Association between Hemodynamically Significant Patent Ductus Arteriosus and Bronchopulmonary Dysplasia. J Pediatr 2015;166:1488-92. [CrossRef]

16. Wynn J, Cornell TT, Wong HR, Shanley TP, Wheeler DS. The host response to sepsis and developmental impact. Pediatrics 2010;125:103141. [CrossRef]

17. Bose CL, Dammann CE, Laughon MM. Bronchopulmonary dysplasia and inflammatory biomarkers in the premature neonate. Arch Dis Child Fetal Neonatal Ed 2008;93:F455-61. [CrossRef]

18. Schlapbach LJ, Aebischer M, Adams M, Natalucci G, Bonhoeffer J, Latzin P, et al; Swiss Neonatal Network and Follow-Up Group. Impact of sepsis on neurodevelopmental outcome in a Swiss National Cohort of extremely premature infants. Pediatrics 2011;128:e348-57. [CrossRef]

19. Lahra MM, Beeby PJ, Jeffery HE. Intrauterine inflammation, neonatal sepsis, and chronic lung disease: a 13-year hospital cohort study. Pediatrics 2009;123:1314-9. [CrossRef]

20. Eriksson L, Haglund B, Odlind V, Altman M, Kieler H. Prenatal inflammatory risk factors for development of bronchopulmonary dysplasia. Pediatr Pulmonol 2014;49:665-72. [CrossRef]

21. Lee SM, Chang M, Kim KS. Blood Culture Proven Early Onset Sepsis and Late Onset Sepsis in Very-Low-Birth-Weight Infants in Korea. J Korean Med Sci 2015;30 Suppl 1:S67-74. [CrossRef]

22. Klinger G, Levy I, Sirota L, Boyko V, Lerner-Geva L, Reichman B; Israel Neonatal Network. Outcome of early-onset sepsis in a national cohort of very low birth weight infants. Pediatrics 2010;125:e736-40.

23. Di Fiore JM, Martin RJ, Gauda EB. Apnea of prematurity--perfect storm. Respir Physiol Neurobiol 2013;189:213-22. [CrossRef]

24. Martin RJ, Di Fiore JM, Walsh MC. Hypoxic Episodes in Bronchopulmonary Dysplasia. Clin Perinatol 2015;42:825-38. [CrossRef]

25. Goldenberg RL, Culhane JF, Iams JD, Romero R. Epidemiology and causes of preterm birth. Lancet 2008;371:75-84. [CrossRef]

26. Mercer BM. Preterm premature rupture of the membranes: current approaches to evaluation and management. Obstet Gynecol Clin North Am 2005;32:411-28. [CrossRef]

27. Strunk T, Doherty D, Jacques A, Simmer K, Richmond P, Kohan R, et al. Histologic chorioamnionitis is associated with reduced risk of lateonset sepsis in preterm infants. Pediatrics 2012;129:e134- 41.

28. Hanke K, Hartz A, Manz M, Bendiks M, Heitmann F, Orlikowsky T, et al; German Neonatal Network (GNN). Preterm prelabor rupture of membranes and outcome of very-low-birth-weight infants in the German Neonatal Network. PLoS One 2015;10:e0122564. [CrossRef]

29. Tapia JL, Agost D, Alegria A, Standen J, Escobar M, Grandi C, et al; NEOCOSUR Collaborative Group. Bronchopulmonary dysplasia: incidence, risk factors and resource utilization in a population of South American very low birth weight infants. J Pediatr (Rio J) 2006;82:1520. [CrossRef]

30. Stoll BJ, Hansen NI, Bell EF, Walsh MC, Carlo WA, Shankaran S, et al; Eunice Kennedy Shriver National Institute of Child Health and Human Development Neonatal Research Network. Trends in Care Practices, Morbidity, and Mortality of Extremely Preterm Neonates, 1993-2012. JAMA 2015;314:1039-51. [CrossRef]

31. Costeloe KL, Hennessy EM, Haider S, Stacey F, Marlow N, Draper ES. Short term outcomes after extreme preterm birth in England: comparison of two birth cohorts in 1995 and 2006 (the EPICure studies). 
BMJ 2012;345:e7976. [CrossRef]

32. Ambalavanan N, Van Meurs KP, Perritt R, Carlo WA, Ehrenkranz RA, Stevenson DK, et al; NICHD Neonatal Research Network, Bethesda, MD. Predictors of death or bronchopulmonary dysplasia in preterm infants with respiratory failure. J Perinatol 2008;28:420-6. [CrossRef]

33. Hartling L, Liang Y, Lacaze-Masmonteil T. Chorioamnionitis as a risk factor for bronchopulmonary dysplasia: a systematic review and metaanalysis. Arch Dis Child Fetal Neonatal Ed 2012;97:F8-17. [CrossRef]

34. Kramer BW, Kallapur S, Newnham J, Jobe AH. Prenatal inflammation and lung development. Semin Fetal Neonatal Med 2009;14:2-7.

35. Lorthe E, Torchin H, Delorme P, Ancel PY, Marchand-Martin L, FoixL'Hélias L, et al. Preterm premature rupture of membranes at 22-25 weeks' gestation: perinatal and 2-year outcomes within a national population-based study (EPIPAGE-2). Am J Obstet Gynecol 2018;219:298. e1-298.e14. [CrossRef]

36. Eriksson L, Haglund B, Odlind V, Altman M, Ewald U, Kieler H. Perinatal conditions related to growth restriction and inflammation are associated with an increased risk of bronchopulmonary dysplasia. Acta Paediatr 2015;104:259-63. [CrossRef]

37. Effect of corticosteroids for fetal maturation on perinatal outcomes. NIH Consensus Development Panel on the Effect of Corticosteroids for Fetal Maturation on Perinatal Outcomes. JAMA 1995;273:413-8.

38. Van Marter LJ, Leviton A, Kuban KC, Pagano M, Allred EN. Maternal glucocorticoid therapy and reduced risk of bronchopulmonary dysplasia. Pediatrics 1990;86:331-6.

39. Roberts D, Dalziel S. Antenatal corticosteroids for accelerating fetal lung maturation for women at risk of preterm birth. Cochrane Database Syst Rev 2006:CD004454. [CrossRef]

40. Carlo WA, McDonald SA, Fanaroff AA, Vohr BR, Stoll BJ, Ehrenkranz RA, et al; Eunice Kennedy Shriver National Institute of Child Health and Human Development Neonatal Research Network. Association of antenatal corticosteroids with mortality and neurodevelopmental outcomes among infants born at 22 to 25 weeks' gestation. JAMA 2011;306:2348-58. [CrossRef]

41. Payne NR, LaCorte M, Karna P, Chen S, Finkelstein M, Goldsmith JP, et al; Breathsavers Group, Vermont Oxford Network Neonatal Intensive Care Quality Improvement Collaborative. Reduction of bronchopulmonary dysplasia after participation in the Breathsavers Group of the Vermont Oxford Network Neonatal Intensive Care Quality Improvement Collaborative. Pediatrics 2006;118 Suppl 2:S73-7. [CrossRef]

42. Lipsett J, Tamblyn M, Madigan K, Roberts P, Cool JC, Runciman SI, et al. Restricted fetal growth and lung development: a morphometric analysis of pulmonary structure. Pediatr Pulmonol 2006;41:1138-45.

43. Sharma P, McKay K, Rosenkrantz TS, Hussain N. Comparisons of mortality and pre-discharge respiratory outcomes in small-for-gestational-age and appropriate-for-gestational-age premature infants. BMC Pediatr 2004;4:9. [CrossRef]

44. Tyson JE, Kennedy K, Broyles S, Rosenfeld CR. The small for gestational age infant: accelerated or delayed pulmonary maturation? Increased or decreased survival? Pediatrics 1995;95:534-8.

45. Simchen MJ, Beiner ME, Strauss-Liviathan N, Dulitzky M, Kuint J, Mashiach S, et al. Neonatal outcome in growth-restricted versus appropriately grown preterm infants. Am J Perinatol 2000;17:187-92.

46. Bardin C, Zelkowitz P, Papageorgiou A. Outcome of small-for-gestational age and appropriate-for-gestational age infants born before 27 weeks of gestation. Pediatrics 1997;100:E4. [CrossRef]

47. Thompson PJ, Greenough A, Gamsu HR, Nicolaides KH. Ventilatory requirements for respiratory distress syndrome in small-for-gestational-age infants. Eur J Pediatr 1992;151:528-31. [CrossRef]

48. Bose C, Van Marter LJ, Laughon M, O'Shea TM, Allred EN, Karna P, et al. Extremely Low Gestational Age Newborn Study Investigators. Fetal growth restriction and chronic lung disease among infants born before the $28^{\text {th }}$ week of gestation. Pediatrics 2009;124:e450-8. [CrossRef]

49. Lal MK, Manktelow BN, Draper ES, Field DJ; Population-based study. Chronic lung disease of prematurity and intrauterine growth retardation: a population-based study. Pediatrics 2003;111:483-7. [CrossRef]

50. Coalson JJ. Pathology of new bronchopulmonary dysplasia. Semin Neonatol 2003;8:73-81. [CrossRef]

51. Day CL, Ryan RM. Bronchopulmonary dysplasia: new becomes old again!. Pediatr Res 2017;81:210-3. [CrossRef] 